\section{Nature of the Action of Emetine upon Entamœba histolytica}

THE fact that emetine exerts a powerful toxic action upon $E$. histolytica, in vivo and in vitro, has long been established ${ }^{1,2}$. The mechanism of this action, however, is far from clear ${ }^{3}$. Furthermore, the endpoint of toxicity of emetine to $E$. histolytica is variable in vitro, depending upon such factors as the nature and reaction of the medium, time of observation, and composition of the bacterial flora which necessarily accompanies the growth of the amoba in culture ${ }^{2,4}$.

In the experiments reported below, emetine hydrochloride was added $(a)$ to cultures of $E$. histolytica in a basic medium of horse serum, rice starch and saline buffered with phosphate to $p \mathbf{H} 7 \cdot 2$, and $(b)$ to suspensions, prepared from such cultures, with a cell density of 150-300 per c.mm. Ten strains of $E$. histolytica were used, each having been isolated originally from cysts in human fæces. One strain $(M)$ was grown with Bact. coli plus $C l$. welchii; the other strains included in their bacterial flora non-lactosefermenting coliforms, Ps. pyocyaneus, enterococci and Clostridia. Acting in the basic medium, emetine did not inhibit the growth or respiration of these bacteria, individually or in combination.

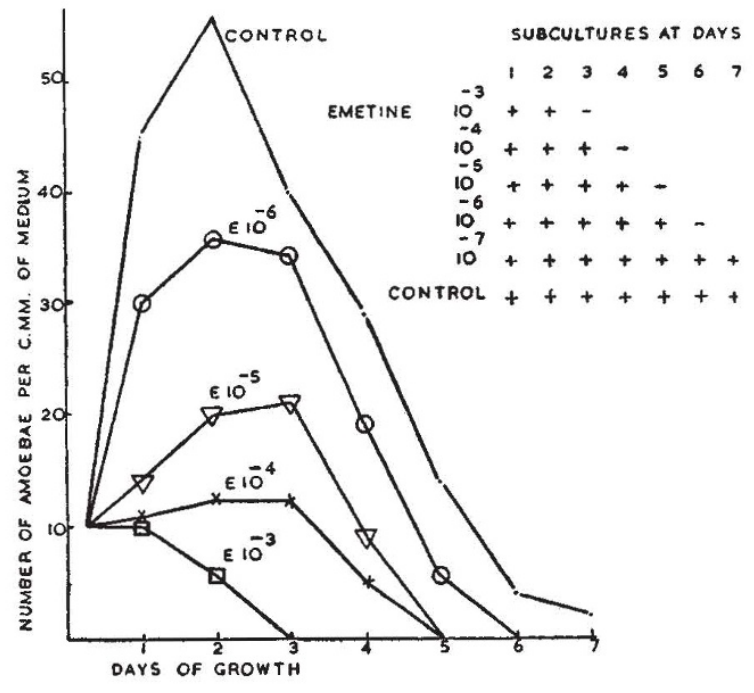

At $p \mathrm{H} 7 \cdot 2$, emetine (in dilutions ranging from $10^{-6}$ to $10^{-7}$ ) sterilized cultures of $E$. histolytica in three to seven days. A study of growth curves showed that this effect was due to a reduction of the propagation. rate (see graph). No division occurred at dilutions of $10^{-3}$ to $10^{-4}$; at higher dilutions there was a progressive increase in the rate of division, and dilutions higher than $10^{-7}$ showed no difference from control cultures. The addition of eysteine $(0.02$ per cent) did not antagonize the action of emetine.

When emetine was added to suspensions of $E$. histolytica, there was no change in the morphology of the cells, and subculture of washed cells was always positive during the first four hours. Thereafter, at dilutions of $10^{-3}$ or less, emetine produced conspicuous degenerative changes in 80-100 per cent of the cells, clearly shown in fresh or iron-hæmatoxylin preparations. Bi-nucleate or dividing cells were absent, and, after 48 hours, subculture was negative. With higher dilutions, there was a proportionate decrease in the number of degenerate cells; dividing cells were present and subcultures made after 48 hours were positive, as in the controls. The morphological changes observed were, in order of appearance: loss of motility, vacuolation, coarse granulation and cen. tral retraction of cytoplasm, loss of nuclear differentiation, and disintegration. These morphological changes were not specific for emetine, since cells comparable in appearance though not in numbers were seen in the control suspensions, especially after 24-48 hours, when the death-rate rose sharply.

From these observations it would seem that emetine does not exert an immediate toxic action upon $E$. histolytica in the fashion of a general proto. plasmic poison. It does, however, have an 'amcebostatic' effect, absolute at a dilution of $10^{-3}$ but still evident at $10^{-7}$ with some strains. Cultures growing in the presence of emetine are sterilized more rapidly than controls for the reason that the cell count reaches a lower maximum, and the culture dies sooner. The end-point of survival of such a culture is determined by the ratio of propagation-rate to natural death-rate of the cells. The cell envelope remains intact, and motility is preserved in the majority of the cells for four hours in the presence of emetine. Surviving cells, transferred from an emetine medium after 24-48 hours, grow normally. Emetine does not produce a definite stage of mitotic arrest, and its action is not antagonized by cysteine, an - SH donor. It seems likely, therefore, that emetine acts upon $E$. histolytica by a highly specific interference, in proportion to its concentration, with some essential cytoplasmic reaction at a phase in the growth of the cell prior to cell division.

G. T. Stewart

Liverpool School of Tropical Medicine. Oct. 19.

${ }^{1}$ Vedder, E. B., J. Amer. Med. Assoc., 62, 501 (1914).

${ }^{2}$ Dobell, C., and Laidlaw, P. P., Parasitology, 18, 206 (1926).

'Dobell, C., Ann. Soc. Belge Méd. Trop., Supp., 27, 201 (1947).

- St. John, J. H., Amer. J. Hyg., 18, 414 (1933).

\section{Effect of the Striga Germination Stimulant on Extension Growth on the Roots of Peas}

THE seeds of Striga hermonthica, like those of certain closely allied parasites, will normally only germinate after they have been treated with a stimulant that is released from the roots of a large variety of species ${ }^{1}$. The situation suggests that the parasite seed is supplied from actively growing host roots with a hormone which is normally required in germination but which is not synthesized by the seed $^{2}$. Moreover, the hormone only acts at a com. paratively late stage in the germination process, and then it has the effect of promoting the extension of the cells of the radicle. When the radicle emerges, at first there is no division at the apex, and the increase in length is apparently due primarily to cell extension. Thus the hormone may be one that promotes cell extension in the root of Striga, and since it is produced from a large variety of species it may be one that stimulates extension growth in roots in general ${ }^{2}$.

This possibility has been investigated by treating segments of pea roots taken from the extending zone with various dilutions of a solution of a concentrate of the hormone. The segments are obtained by cutting out of intact roots the zone extending from 1.5 to $3.0 \mathrm{~mm}$. from the tip. Observations can be made rapidly with this material, and extension 